\title{
Structural composites hybridized with epoxy compatible polymer/MWCNT nanofibrous interlayers
}

\author{
K. Bilge, E. Ozden-Yenigun, E. Simsek, Y.Z. Menceloglu, M. Papila*,1 \\ Faculty of Engineering and Natural Sciences, Advanced Composites and Polymer Processing Laboratory (AC2PL), Sabanci University, Istanbul, Turkey
}

\section{A R T I C L E I N F O}

\section{Article history:}

Received 14 April 2012

Accepted 8 July 2012

Available online 15 July 2012

\section{Keywords:}

A. Nanocomposites

A. Structural composites

E. Electro-spinning

B. Delamination

Interlayer

\begin{abstract}
A B S T R A C T
Surface reactive $\mathrm{P}(\mathrm{St}$-co-GMA) copolymer and $\mathrm{P}(\mathrm{St}$-co-GMA)/MWCNT fibrous mats are placed onto a conventional carbon fiber/epoxy prepreg as interlayer reinforcing material. Experimental observations are used to demonstrate excellent epoxy wetting and structural compatibility of the interlayers chemically tuned for the epoxy matrix. Comparisons of increase in mechanical performance by incorporating $\mathrm{P}(\mathrm{St}$ Co-GMA) and P(St-co-GMA)/MWCNT interlayers also show the contribution of MWCNT presence in the copolymer nanofibers. Flexural strength and stiffness of (0/0/0) and (90/0/90) laminates increase up to $17 \%$ when the nanocomposite interlayers are integrated. Cross-sectional SEM analyses of the failure surfaces suggest reinforcing ability of interlayers both against transverse cracking and delamination. Further examination for the delamination resistance is presented by the End Notched Flexure (ENF) tests. An improvement up to $70 \%$ in mode II strain energy release rate $\left(G_{\text {IIC }}\right)$ is recorded for the laminates with nanocomposite interlayers. The resistance against transverse matrix cracking in the presence of interlayers is also elaborated. Charpy-impact and transverse-tension tests result in up to $20 \%$ and $27 \%$ increase in the impact energy absorbance and transverse tensile strength, respectively. Overall, the test results suggest that mechanical behavior of the laminates is enhanced by the nanofibrous interlayers chemicallytuned for epoxy crosslinking, with no weight penalty.
\end{abstract}

(ㄷ) 2012 Elsevier Ltd. All rights reserved.

\section{Introduction}

Intra-and inter-laminar resistance to failure in laminated composite materials has been an active and constantly growing research field. Improvement in failure resistance is typically sought by (i) altering the constituent properties, (ii) introducing effective sub-phases and reinforcement without significant weight penalty including ply stitching and z-pinning applications. Matrix toughening and interlayer toughening, for instance, have emerged to increase delamination resistance [1]. Kim and Reneker [2] introduced an innovative idea and demonstrated the utility of electrospun nanofibers as potential bulk toughening elements. In line with Reneker's work, Dzenis [3,4] explored the use of electrospun nanofibers as interlayer toughening elements within the traditional laminated composites. Dzenis observed that entangled nanofibers improve interlaminar fracture resistance much like the hooks and loops in Velcro and also play a part in crack deflection, nanofiber pull-out, plastic deformation, and crack bridging [4]. This pioneering idea was then applied to several composite

\footnotetext{
* Corresponding author. Tel.: +90 2164839540; fax: +90 2164839550.

E-mail address: mpapila@sabanciuniv.edu (M. Papila).

1 Stanford University, Aero/Astronautics.
}

systems and studied under various testing conditions [5-10] which were thoroughly reviewed and discussed by Zucchelli et al. [11].

Targeting improved toughness, several studies offered the use of carbon nanotubes as toughening elements to increase ply by ply sticking and delamination resistance $[12,13]$.

While these studies have been paving the way to the integration of nanocomposites into traditional composites, research on their modeling aspects have also been intensified. Effective modeling strategies of various complexities can be used to understand the characteristics [14-16] and to explore the potential of the nano composites [17]. Review articles by Zeng et al. [14], Hu et al. [15] and more recently Llorca et al. [16] provide insight to the stateof-the-art on computational techniques, ranging from molecular dynamics simulations to traditional finite element analysis, to address the multi-scale nature of the nanocomposite/composite world. It is our interpretation that integration of nanocomposites, nanofibrous filler forms in particular, into conventional structural composites calls for both further data generation and multiscale modeling or framework for accurate mechanical/structural behavior predictions.

Our present work is intended to contribute the experimental demonstration and data generation of the nanofiber reinforced interlayers in laminated composites. In support of the effective use of electrospun nanofibers in structural composites, our previ- 
ous efforts $[18,19]$ introduced the concept of tailoring or designing the chemistry of electrospun fiber and their interface with the polymer matrix. Our experiments revealed that polystyrene-coglycidyl methacrylate $\mathrm{P}(\mathrm{St}-\mathrm{co}-\mathrm{GMA})$ is a promising base polymer for nanofiber production due to its chemical compatibility with the crosslinking epoxy systems in composite applications.

We initially aim herein to show the potential of electrospun $\mathrm{P}$ (St-co-GMA)/MWCNT based nanofibers as interlayers in conventional carbon fiber reinforced epoxy laminates. Since the choice of nanofiber chemistry points to the desirability of nanofiber-matrix compatibility and complete epoxy wettability reinforcing abilities of the nanofibrous interlayers against transverse matrix cracking and delamination were explored. The overall flexural performance increase through the incorporation of nanofibrous interlayers is reported. Resistance against delamination was measured in mode II by end notched flexure (ENF) tests whereas transverse matrix cracking resistance was primarily characterized by transverse Charpy impact tests and transversial tension tests. The effect of MWCNT presence in the fibrous structure was further evaluated through parallel testing of $\mathrm{P}(\mathrm{St}-\mathrm{co}-\mathrm{GMA})$ interlayered laminates.

\section{Experimental procedure and characterization}

\subsection{Electrospinning process and laminate manufacturing}

For the synthesis of $\mathrm{P}(\mathrm{St}-\mathrm{co}-\mathrm{GMA})$ copolymer our previously reported methodology was applied [17]. Polymer solutions were prepared by dissolving $\mathrm{P}$ (St-co-GMA) $30 \mathrm{wt}$.\% in DMF and stirring for $3 \mathrm{~h}$. MWCNTs were added to the copolymer solution at $1 \mathrm{wt} . \%$ of the copolymer in the solution and magnetically stirred for $24 \mathrm{~h}$ to ensure a good dispersion. Applied voltage, solution flow rate and tip to ground distance were set at $15 \mathrm{kV}, 30 \mu \mathrm{L} / \mathrm{h}$ and $10 \mathrm{~cm}$, respectively during electrospinning. The polymer solution was electrospun directly onto carbon/epoxy prepreg layers. Consequently, a thin homogenous layer of nanofibers, was electrospun on the prepreg surface forming the interlayer with an additional weight as low as $0.2 \%$ of the prepreg ply weight. Note that whether being subject to electrospin or not, out-of-the freezer time and conditions of the prepreg plies were kept consistent throughout the study. After stacking the plies for intended laminates, each stack was put on a metalic tooling plate along with a release film and peel ply. Another sheet of peel ply was then laid on the pile of plies followed by a nonwoven breather layer. Next, the whole lay-up was vacuum bagged and kept under vacuum during the cure cycle. The cure temperature was primarily selected in accordance with the glass transition temperature of $\mathrm{P}(\mathrm{St}$-co-GMA) copolymer fibers [18] (Tg is around $100^{\circ} \mathrm{C}$ ). Prepreg stacks were heated up $100{ }^{\circ} \mathrm{C}$ at a rate of $0.85^{\circ} \mathrm{C} / \mathrm{min}$, and hold time was $48 \mathrm{~h}$. Through screening flexural tests, this prolonged cure cycle resulted in very close flexural performance on UD specimens compared to typical cure cycle at $132^{\circ} \mathrm{C}$ for four hours: flexural modulus $45.7 \pm 0.8$ vs. $46.5 \pm 1.6 \mathrm{GPa}$ and flexural strength $875 \pm 15$ vs. $867 \pm 19 \mathrm{MPa}$.

\subsection{Mechanical testing}

Mechanical tests were performed using of Zwick Roell Z100 Universal Testing Machine and CEAST Resil Impactor machine. Loading rates and machine accessories were set up in accordance with the testing types namely, unnotched Charpy impact, three point bending, end notched flexure and transversal tension tests.

Flexural strength and modulus of interlayered and non-interlayered, (0/0/0) and (90/0/90) laminates were calculated via three point bending tests. For interlayered laminates, two interlayers on the interlaminar planes separated by a carbon/epoxy ply were added. Test configurations and preparation of the specimens were done according to ASTM D790 testing standards. Mode II critical strain energy release rate $\left(G_{\text {IIc }}\right)$ of the composite laminates was investigated by ENF tests. $(0)_{4}$ uni-directional laminates containing mid-surface delamination were tested under three point bending load configuration. A non-adherent, $30 \mu \mathrm{m}$ thick film layer was inserted to create the initial delamination during consolidation of the laminates. Unlike the 3-point bending tests the interlayer was inserted only at the midplane. Tests were conducted with a constant displacement rate of $1 \mathrm{~mm} / \mathrm{min}$ and $G_{\text {IIc }}$ values were calculated using direct beam theory [20]. Transverse tensile tests were performed in accordance with ASTM D3039 test standards. Laminates stacked as $(90)_{4}$ having interlayers between the adjacent plies were used. Tests were conducted with a constantdisplacement rate of $1 \mathrm{~mm} / \mathrm{min}$. Maximum stress at failure was measured to determine the tensile strength of the tested laminates. Charpy impact tests were performed in accordance with the ASTMD 6110 testing standards. Specimens of $(0)_{4}$ laminates were subjected to transversal impact loading from the longitudinal edge. Interlayered specimens contained 3 layers of interply reinforcement. An impact hammer of $4 \mathrm{~J}$ energy capacity was used with an initial release angle of $150^{\circ}$. Amount of energy absorbed upon transverse impact was recorded.

\subsection{Surface and cross sectional analysis}

Cross section and fracture surface analysis of the composite laminates were carried out with a LEO Supra VP35 field emission scanning electron microscope after sputter deposition of a thin conductive carbon coating onto the samples. Distribution of MWCNTs in the nanofibers was investigated with a JEOL 2100 high resolution transmission electron microscope. Contact angle measurements of the epoxy resin on the electrospun fiber mats were performed using Kruss GmbH DSA 10Mk2 goniometer using DSA 1.8 software. $5 \mathrm{mg}$ droplets of resin/hardener mixture were put on the electrospun P(St-co-GMA) fibrous mat surface to investigate the epoxy wetting.

\section{Results and discussion}

\subsection{MWCNTs in $P($ St-co-GMA) nanofibers}

A systematic study on the electrospinning of $\mathrm{P}(\mathrm{St}-\mathrm{co}-\mathrm{GMA}) /$ MWCNT fibers was carried out and reported by Ozden et al. [21]. We implemented the process parameters and material proportions suggested for successful introduction of the MWCNTs and the morphology of the fibrous webs [21]. Fig. 1 presents the TEM analysis of $\mathrm{P}(\mathrm{St}-\mathrm{co}-\mathrm{GMA})$ electrospun nanofibers composed of $1 \mathrm{wt} . \%$ MWCNTs and demonstrates that MWCNTs were efficiently placed in the polymeric nanofibers as supplementary pin-like reinforcing elements.

\subsection{Epoxy wettability and structural compatibility of P(St-co-GMA)/ MWCNT interlayers}

Fig. 2a and b shows the SEM images of P(St-co-GMA)/MWCNTs.

Nanofibers electrospun onto the prepreg surfaces at room temperature. Average fiber diameter ranged from 300 to $600 \mathrm{~nm}$. When the electrospun mat was heated up to $100^{\circ} \mathrm{C}$, the non-woven fibrous morphology was transformed into a net-like structure composed of fibers connected at micron scale bead-like nodal points (Fig. $2 \mathrm{c}$ and d). This change in the microstructure suggests the presence of a good interaction between fibrous interlayers and matrix phase at the laminate curing temperature. The matrix and nanofiber interaction was also observable macroscopically. 

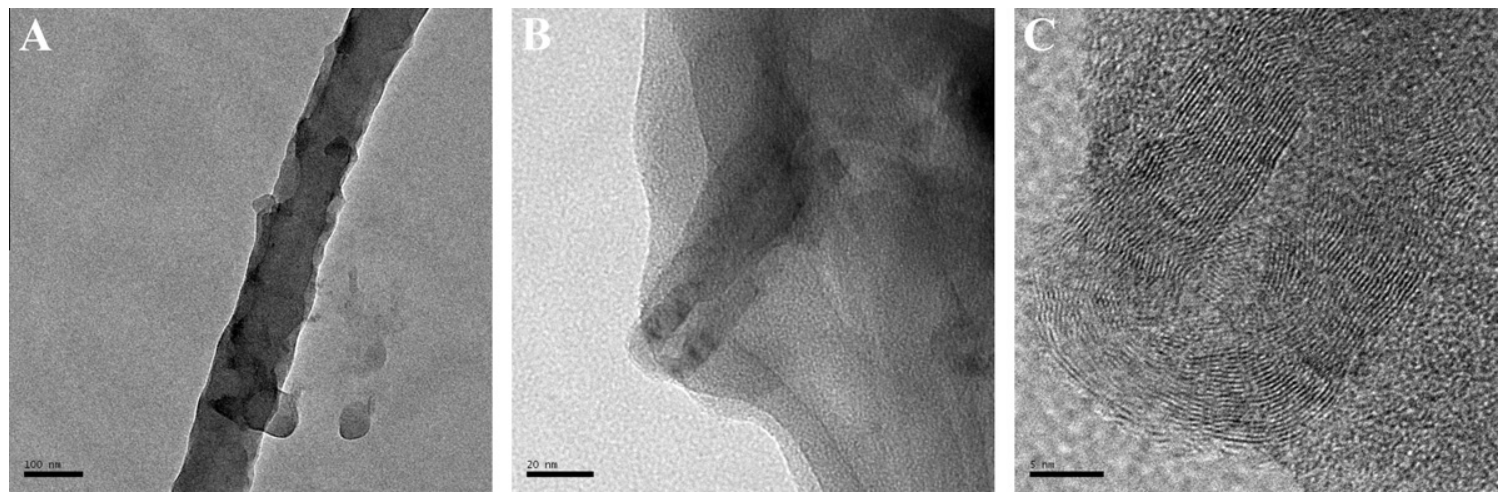

Fig. 1. TEM images of MWCNTs on nanofiber surfaces. (a) A single fiber. (b) Slice view of a single fiber. (c) Zoomed view of MWCNTs.
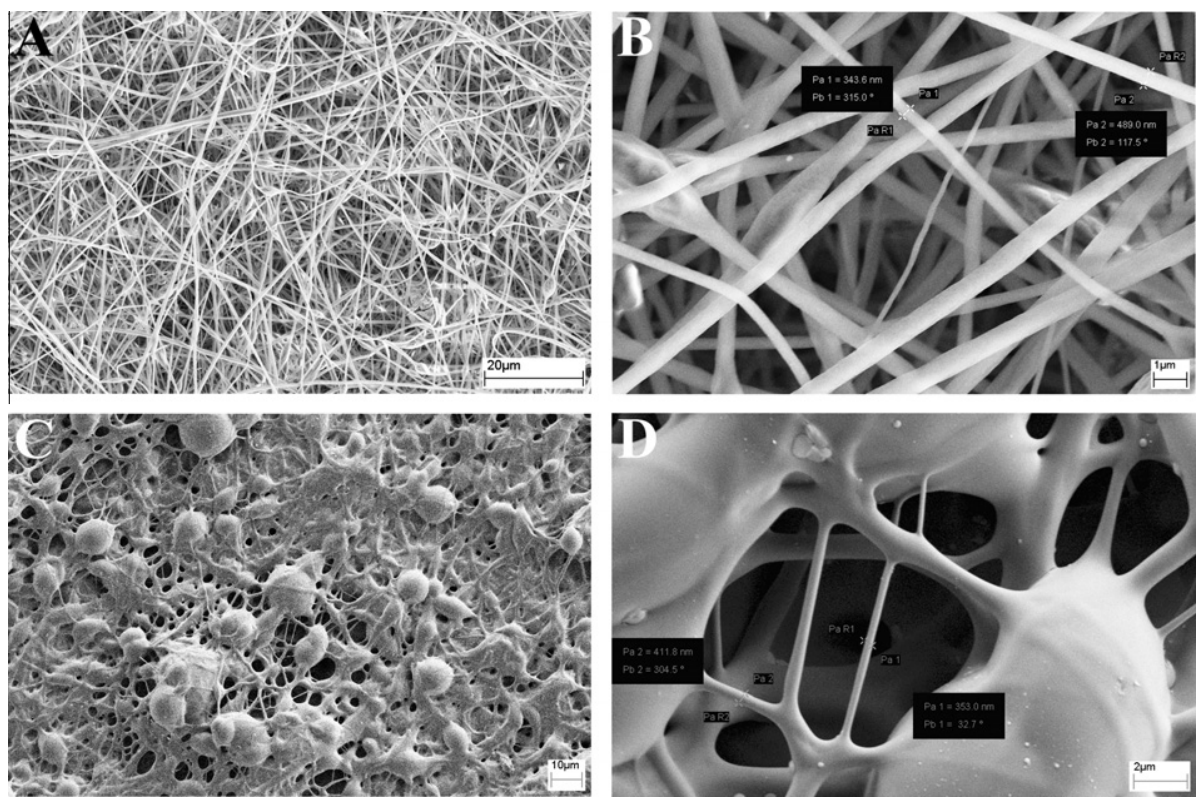

Fig. 2. Nanofiber morphologies on the prepreg surfaces: (a and b) at room temperature and (c and d) at $100{ }^{\circ} \mathrm{C}$
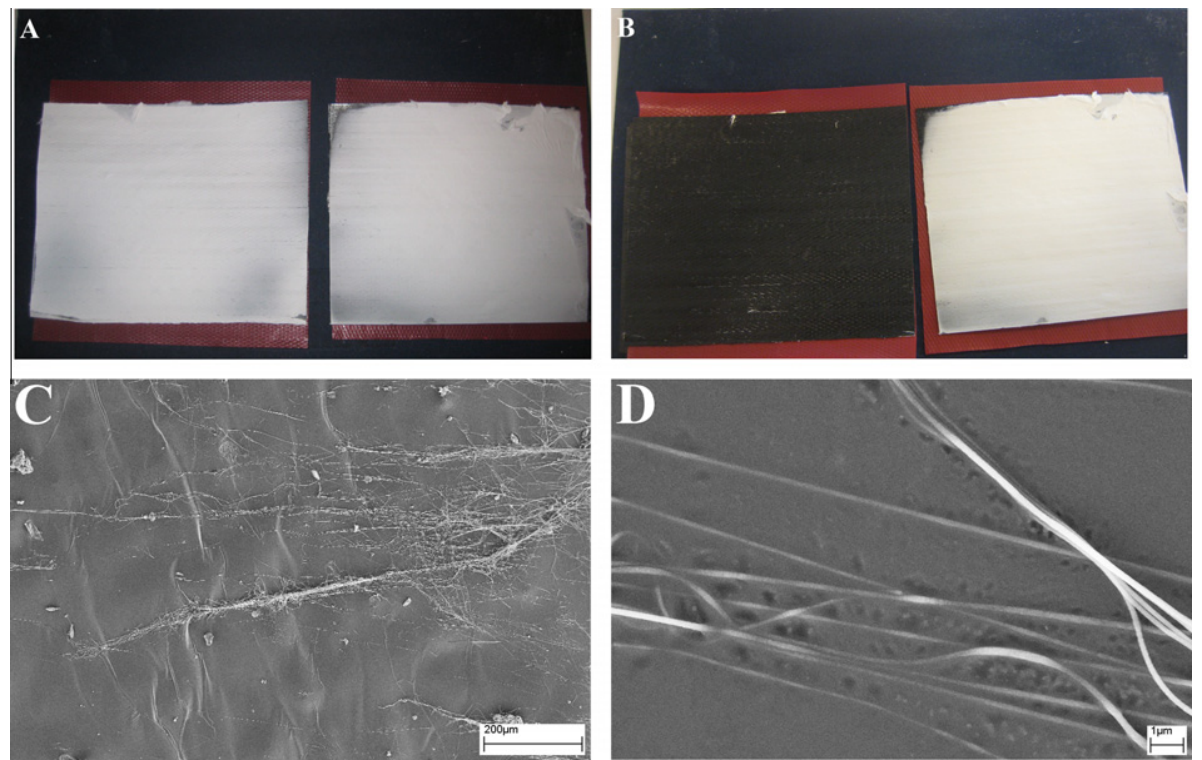

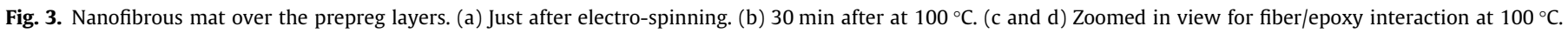




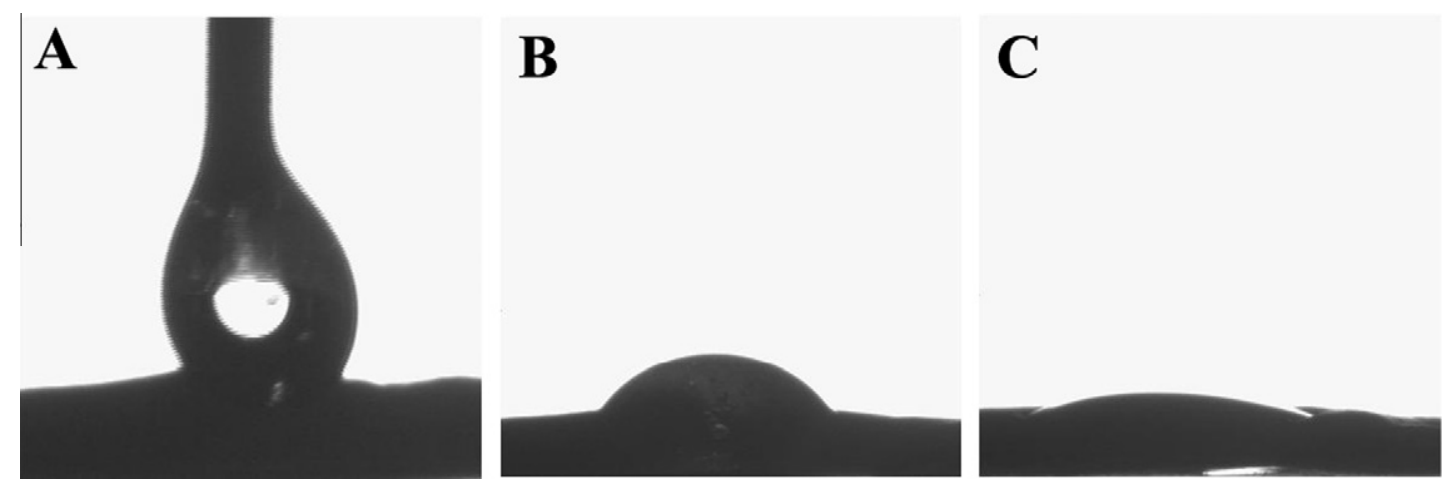

Fig. 4. An epoxy/hardener drop on the P(St-co-GMA)/MWCNT surface.

Fig. 3 shows photograph of the electrospun layer-prepreg system kept at curing temperature $100{ }^{\circ} \mathrm{C}$ (left hand side) and pristine samples at room temperature (right hand side) for comparison. It was quite visible that when the prepreg with the electrospun fibrous layer coat was heated, the epoxy matrix penetrated into the fibrous layer and wetting of the layer was completed even standing free with no vacuum bagging pressure (Fig. 3b). Recall that the zoomed-in view of the surface of unheated laminate in Fig. 3b appeared as shown in Fig. 2a. However, when the temperature was increased, those layers of the majority of the nanofibers were no longer visible due to progressive self-wetting (Fig. 3c and d). More formal investigation of the wettability was performed via contact angle measurements with epoxy/hardener mixture on the surface of the electrospun mat. When a droplet of epoxy/hardener mixture was put on the electrospun mat, it advanced and wetted the surface by leaving an average contact angle as low as $26.5 \pm 6.1^{\circ}$, as shown in Fig. 4 . This result indicated that the viscous epoxy/hardener mixture could penetrate through the micropores in the fibrous surface morphology without challenging a remarkable capillary pressure due to the attractive forces [22], which is another indication of the chemical compatibility between the copolymer and the epoxy system.

\subsection{Flexural performance by three-point bending tests}

Comparison of three point bending tests on laminates with and without fibrous interlayers showed that their addition led to increase in both flexural strength and modulus of the samples. The nanofibrous interlayers (denoted by I) within the laminates $(0 / \mathrm{I} /$ $0 / \mathrm{I} / 0$ ) resulted in $11 \%$ and $17 \%$ increase in the flexural strength $\left(\sigma_{\text {flex }}\right)$ and flexural modulus $\left(E_{\text {flex }}\right)$, respectively (2nd and 3rd columns of Table 1 ). Introduction of nanotubes by $1 \%$ weight to the copolymer fibers led to a further improvement adding up to $16 \%$ and $25 \%$ increase in the corresponding values compared to results without nanocomposite interlayers incorporated. Comparing (90/ $0 / 90)$ vs. (90/I/0/I/90) laminates, $\mathrm{P}(\mathrm{St}-\mathrm{co}-\mathrm{GMA})$ nanofibrous interlayers increased both the flexural strength and modulus of the samples by $17 \%$. The increase in these values were $21 \%$ and $29 \%$ with P(St-co-GMA)/MWCNT interlayers.

Post-failure SEM analyses on cross section of the specimens revealed that the lamination sequence was a factor in the fracture mode. Two distinct active failure mechanisms, transverse matrix cracking and/or delamination, were observed in (0/0/0) laminates. Co-existence of the two failure mechanisms on the samples is attributed to the inability of the three point bending test to create pure shear conditions. An example is shown in the SEM image of a $(0 / 0)$ interface represented in Fig. 5a where the two corresponding mechanisms were indicated with arrows (1: transverse matrix cracking and 2: delamination). Oblique intra-ply damage initiated at the end of delamination growth occurred due to the presence of high stress regions at the contact of the loading tip. The flexural strength and modulus increase reported by the three-point bending tests characterized both delamination resistance and matrix toughening introduced by the addition of the interlayer. This double effect of the interlayer was also studied and introduced by Sihn et al. [5].

With (90/0/90) lamination sequence, fracture mechanism was driven by $90^{\circ}$ plies. The presence of $90^{\circ}$ plies at the outer surface ensured the arising of interlaminar stresses at 90/0 interface due to the stiffness mismatch. In addition the inherent weak links of

Table 1

Mechanical test results.

\begin{tabular}{|c|c|c|c|c|c|}
\hline Specimen layup & $\sigma_{\text {flex }}{ }^{\mathrm{c}}(\mathrm{MPa})$ & $E_{\text {flex }}{ }^{\mathrm{c}}(\mathrm{GPa})$ & $G_{\text {IIC }}{ }^{\mathrm{d}}\left(\mathrm{kJ} / \mathrm{m}^{2}\right)$ & Energy absorbed ${ }^{\mathrm{e}}(\mathrm{kJ})$ & $\sigma_{2 \text { ult }}{ }^{\mathrm{f}}(\mathrm{MPa})$ \\
\hline$(0 / 0 / 0)$ & $875 \pm 16$ & $45.7 \pm 0.8$ & - & - & - \\
\hline$\left(0 / \mathrm{I}^{\mathrm{a}} / 0 / \mathrm{I}^{\mathrm{a}} / 0\right)$ & $965 \pm 17$ & $53.5 \pm 0.9$ & - & - & - \\
\hline$\left(0 / \mathrm{I}^{\mathrm{b}} / 0 / \mathrm{I}^{\mathrm{b}} / 0\right)$ & $1002 \pm 14$ & $57.3 \pm 0.4$ & - & - & - \\
\hline$(90 / 0 / 90)$ & $243 \pm 6$ & $4.9 \pm 0.2$ & - & - & - \\
\hline$\left(90 / \mathrm{I}^{\mathrm{a}} / 0 / \mathrm{I}^{\mathrm{a}} / 90\right)$ & $282 \pm 9$ & $6 \pm 0.1$ & - & - & - \\
\hline$\left(90 / \mathrm{I}^{\mathrm{b}} / 0 / \mathrm{I}^{\mathrm{b}} / 90\right)$ & $296 \pm 6$ & $6.4 \pm 0.1$ & - & - & - \\
\hline$(0 / 0 / 0 / 0)$ & - & - & $0.95 \pm 0.03$ & $1.72 \pm 0.05$ & $26.5 \pm 0.7$ \\
\hline$\left(0 / 0 / I^{a} / 0 / 0\right)$ & - & - & $1.47 \pm 0.04$ & - & - \\
\hline$\left(0 / 0 / \mathrm{I}^{\mathrm{b}} / 0 / 0\right)$ & - & - & $1.60 \pm 0.10$ & - & - \\
\hline$\left(0 / \mathrm{I}^{\mathrm{a}} / 0 / \mathrm{I}^{\mathrm{a}} / 0 / \mathrm{I}^{\mathrm{a}} / 0\right)$ & - & - & - & $1.86 \pm 0.10$ & $31.2 \pm 0.6$ \\
\hline$\left(0 / \mathrm{I}^{\mathrm{b}} / 0 / \mathrm{I}^{\mathrm{b}} / 0 / \mathrm{I}^{\mathrm{b}} / 0\right)$ & - & - & - & $2.13 \pm 0.20$ & $33.6 \pm 0.7$ \\
\hline
\end{tabular}

\footnotetext{
a $\mathrm{P}(\mathrm{St}-\mathrm{co}-\mathrm{GMA})$ interlayers.

b $\mathrm{P}(\mathrm{St}-\mathrm{co}-\mathrm{GMA}) / \mathrm{MWCNT}$ interlayers

c Three point bending.

d End notched flexure.

e Charpy impact.

f Transverse tensile.
} 

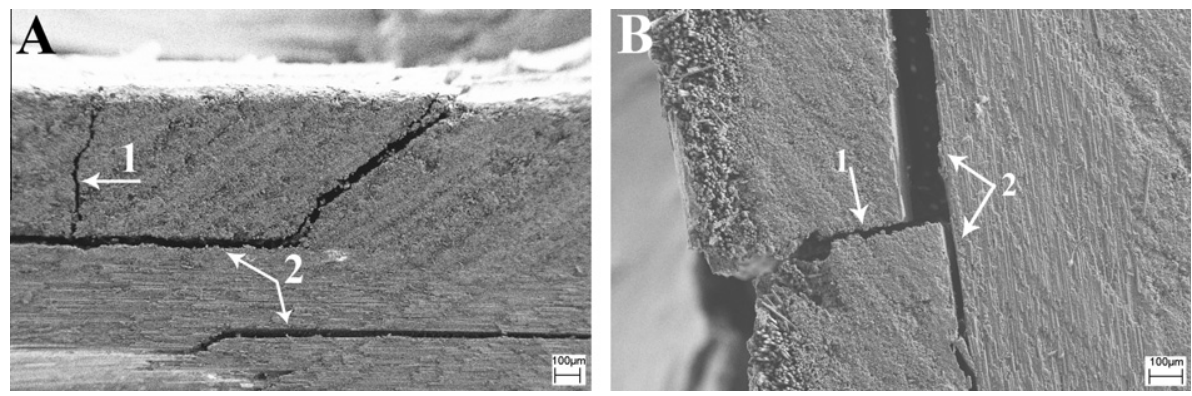

Fig. 5. Cross-sectional view of fractured three point specimens. (a) (0/0/0) and (b) (90/0/90).

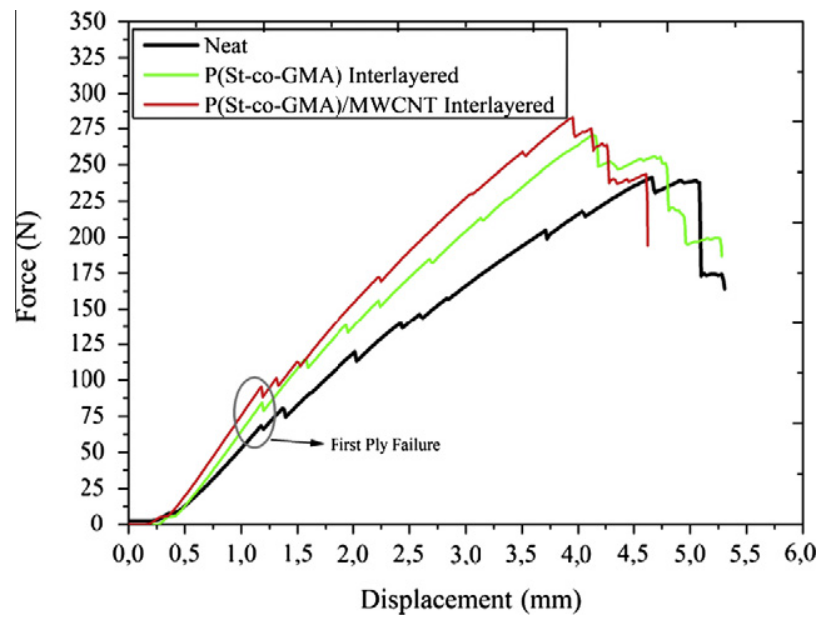

Fig. 6. Representative force-displacement test curves for (90/0/90) laminates.

$90^{\circ}$ plies to tensile loads triggered a matrix crack induced failure on the bottom ply during bending loading (Fig. 5b). Fig. 6 shows the representative flexural force-displacement curves of specimens with and without nanocomposite interlayers. The initial load drop (encircled in Fig. 6) corresponds to the first ply failure due to the critical matrix cracking on the bottom $90^{\circ}$ ply subjected to tension. Note that the local matrix failure did not cause the ultimate failure. Instead a stable crack growth characterized by the load drops in Fig. 6 was observed and the final fracture occurred when 90 (failed)/0 interface progressed to delamination. Hence the overall flexural performance was governed by two major failure mechanisms. The increased resistance against initial matrix cracking may be noted by comparing the first ply failure loads whereas the delamination resistance of laminates may be compared by the ultimate load values. It is clearly visible from Fig. 6 that the interlayer addition worked well for both mechanisms as it was suggested for $(0 / 0 / 0)$ laminates.

\subsection{Mode II strain energy release rate by ENF tests}

$\mathrm{P}$ (St-co-GMA) interlayer presence at the pre-crack tip increased $G_{\text {IIc }}$ by $55 \%$ (4th column Table 1 ). Further increase up to $70 \%$ in $G_{\text {IIc }}$ by $\mathrm{P}(\mathrm{St}-\mathrm{co}-\mathrm{GMA}) / \mathrm{MWCNT}$ interlayers suggests that the toughening is also correlated with the incorporation of the MWCNTs on electrospun fiber surfaces.

Failure of ENF specimens was observed as dominated by unstable crack growth parallel to the interlaminar plane with a sudden load drop. Formation of an unstable crack growth can be considered as an inherent characteristic in the testing of UD laminates under ENF test configurations with constant displacement rate [23]. Further analysis of the fracture surfaces also suggested that the increase observed in $G_{\text {IIc }}$ was directly associated with the active role of interlayers on the fracture resistance. Common hackle patterns typically due to the micro-crack coalescence [24] all along the crack pathway are clearly visible on specimens without nanocomposite interlayers (Fig. 7a). Whereas the hackle patterns for the interlayered specimens were either locally altered and replaced by a more complex structure or enlarged in size (Fig. 7b).

A different fracture mode was noted as the capillary-like damage marks indicated in Fig. 7c. These damage marks were observed both in the areas consisting of epoxy-interlayer complex (left and right arrows) and around carbon fibers (center arrow) that is surrounded by epoxy-interlayer complex (Fig. 7d). Close examination of the fracture pattern seen in Fig. $7 \mathrm{~d}$ revealed the presence of micro-crack formation through the interlayer-epoxy complex. This observation can be further supported by the cut-like damage marks inside of the interlayer-epoxy complex for which a zoomed-in image is shown in Fig. 7e. Furthermore, the epoxy matrix and interlayers were not separated with a distinct interface, which was consistent with the structure shown in Fig. 2c (image taken on ply).

\subsection{Un-notched Charpy impact test results}

The effect of interlayers against the transverse micro-cracking as reported by preliminary three point bending results were further explored by Charpy impact tests. Unidirectional composite specimens were subjected to transversal impact (impact head to hit against the specimen longitudinal side wall rather than its surface) in order to create a failure initiated by sudden matrix cracking. An average increase up to $20 \%$ was recorded with the interlayered specimens. Moreover, in consistence with the results reported in previous sections, the presence of MWCNT on the fiber surfaces played a similar role in the overall performance of the laminates under impact loading conditions (5th column in Table 1).

\subsection{Transverse tensile test results}

Transverse tensile tests of the uni-directional laminates offer an easy way to test for the effect of interlayers on the matrix dominated characteristics. Integration of $\mathrm{P}(\mathrm{St}-\mathrm{co}-\mathrm{GMA})$ and $\mathrm{P}(\mathrm{St}-\mathrm{Co}-$ GMA)/MWCNTs interlayers on each ply resulted in $17 \%$ and $27 \%$ increase, respectively in transverse tensile strength (6th column of Table 1), with no weight penalty. These results correlate well with the previous Charpy impact tests where toughening by nanocomposite interlayers was associated with the increase in absorbed impact energy. Ultimate fracture of the UD transverse tension specimens was in the matrix cracking mode as expected. The cross sectional analysis of failed specimens further revealed the difference in ply-to-ply resin structure at the interlaminar plane which 

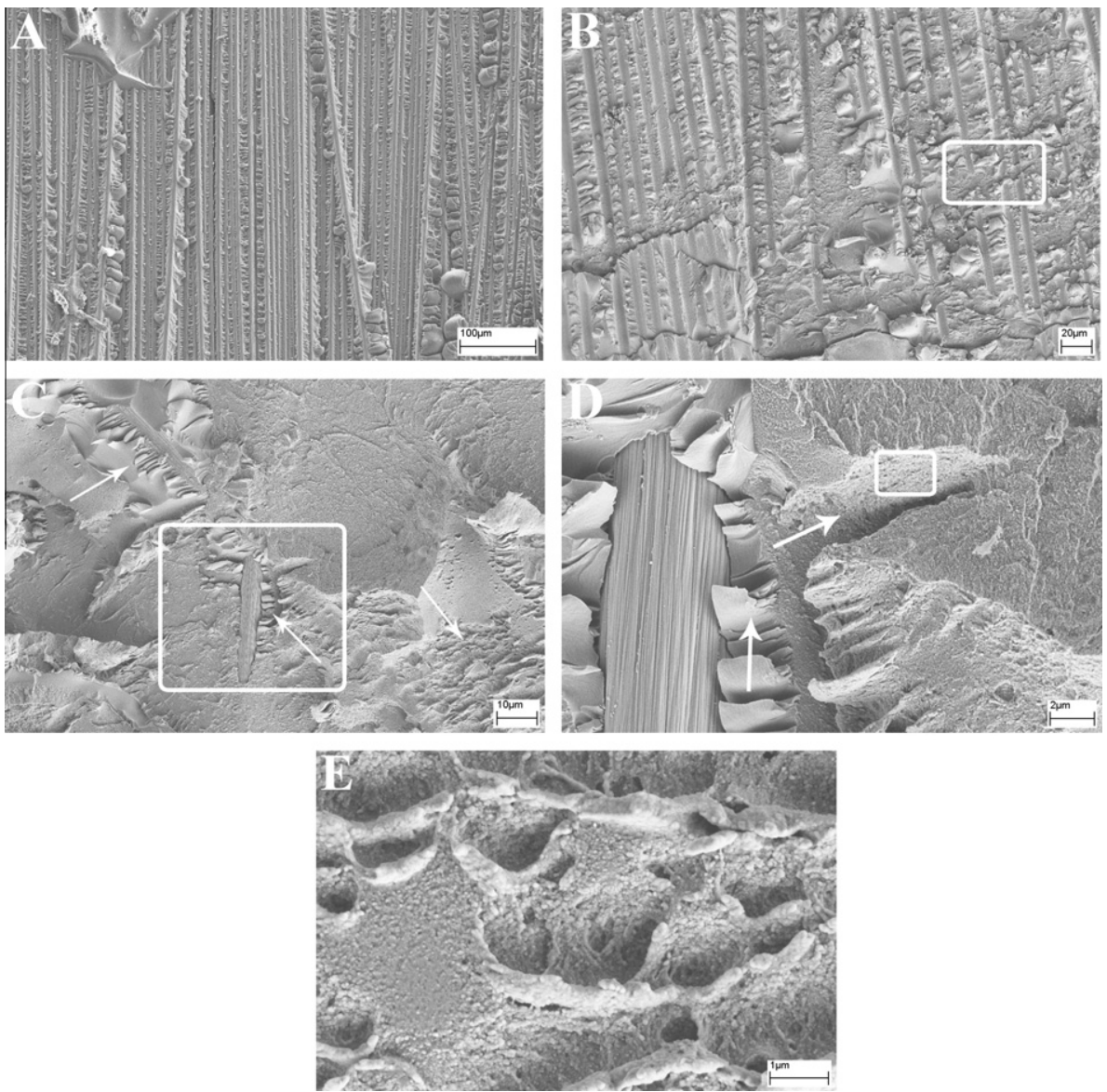

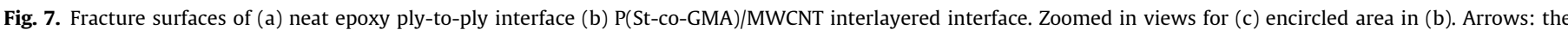
distinguishable damage marks (d) encircled area in (c), arrows: two distinct failure regions (carbon fiber interface and through interlayer/epoxy complex). (e) Encircled area in (d). Damage marks on interlayer/epoxy complex.
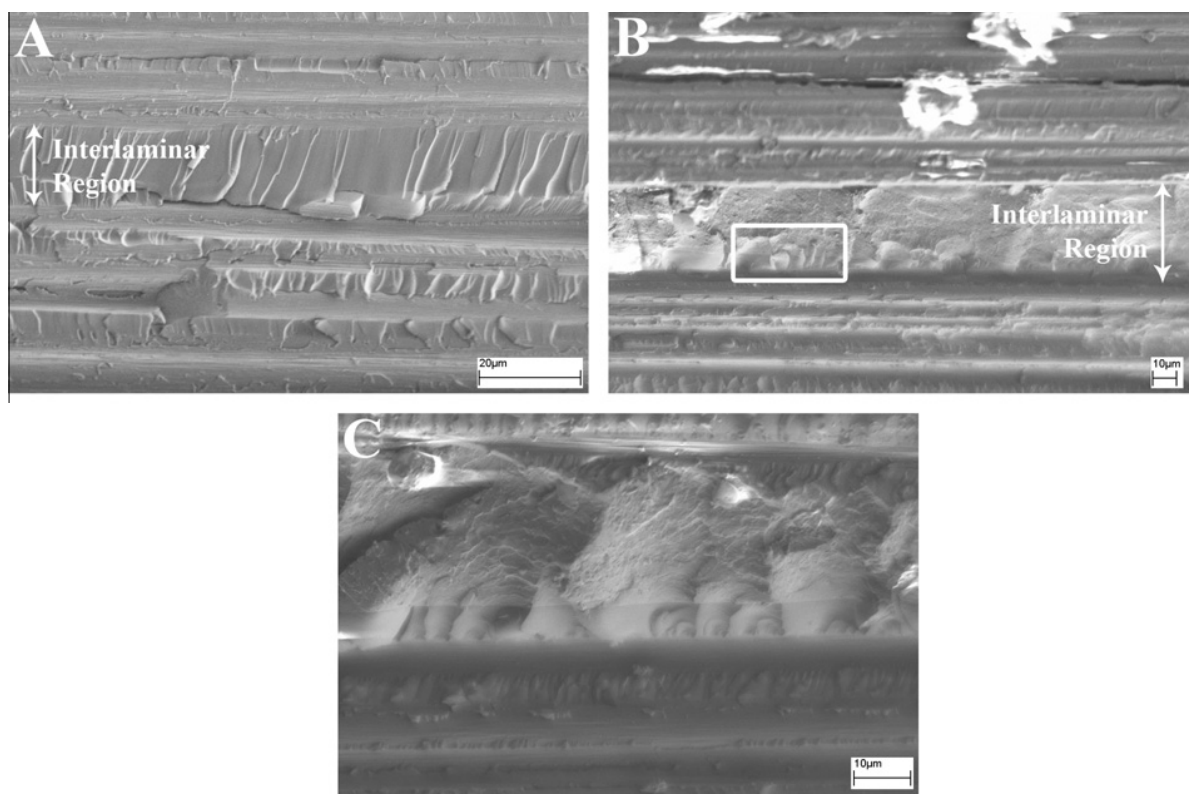

Fig. 8. Cross-sectional view of a fractured transverse tensile UD test specimen (a) neat epoxy ply-to-ply interface and (b) P(St-co-GMA)/MWCNT interlayered. (c) Zoomed in view of encircled area in 8.

was differentiated by the space between two subsequent carbon fibers as indicated in Fig. 8 .
Fig. 8a corresponds to the cross-sectional view of a laminate of neat epoxy interlayer where the damage marks occurred due to the 
resin fracture are clearly visible and the between-ply and in-ply resin fracture patterns are consistent. On the contrary, the resin morphology between the plies(ply- to-ply interface) and inside the plies were different on the cross-sectional fracture surface of the $\mathrm{P}$ (St-co-GMA)/MWCNTs interlayered specimens, as can be seen in Fig. $8 b$.

\section{Conclusion}

Electrospinning process was used to obtain nanofibrous $\mathrm{P}(\mathrm{St}-$ co-GMA) and P(St-co-GMA)/MWCNT interlayers on uncured carbon/epoxy prepreg surfaces. Chemistry tuned compatibility of $\mathrm{P}$ (St-co-GMA) nano fibers with the epoxy matrix and its ability to confine MWCNTs were assessed. Three point bending test results showed significant amount of increase in both flexural strength and flexural modulus up to $25 \%$ and $29 \%$ respectively. The mode II delamination resistance was increased up to $70 \%$ and noticeable changes in the fracture modes were observed when nanocomposite interlayers were incorporated into the laminates. The resistance against transverse matrix cracking was tested under impact and tension loads. Interlayered Charpy impact specimens absorbed $20 \%$ more energy than the non-interlayered ones. Transverse tensile strength of the interlayered UD specimens was about $27 \%$ higher than the non-interlayered specimens. Cross sectional fracture surface analysis suggested compatibility of interlayers with the surrounding matrix, which we attributed as the reason for resistance against matrix cracking. Chemical characteristics with the choice of $\mathrm{P}(\mathrm{St}-\mathrm{co}-\mathrm{GMA})$ also enable the incorporation of MWCNTs during electrospinning, which eventually increased further the mechanical performance of the interlayered laminates with a very low weight penalty (at about $0.2 \%$ by a single fibrous layer).

\section{Acknowledgements}

Graduate student supports from TUBITAK (BIDEB) and Grant number 109M651. Support of the European Commission under the Marie Curie International Outgoing Fellowship Programme, Grant FP7-PEOPLE-2010-IOF-274737.

\section{References}

[1] Tsotsis TK. Interlayer toughening of composite materials. Polym Compos 2009;30(1):70-86.

[2] Kim JS, Reneker DH. Mechanical properties of composites using ultra fine electrospun fibers. Polym Compos 1999;20(1):124-31.
[3] Dzenis Y, Reneker DH. Delamination resistant composites prepared by small diameter fiber reinforcement at ply interfaces. US patent $626533 ; 2001$

[4] Dzenis Y. Structural nanocomposites. Science 2008;319(5862):419-20.

[5] Sihn S, Kim RY, Huh W, Lee KH, Roy AK. Improvement of damage resistance in laminated composites with electrospun nano-interlayers. Compos Sci Technol 2008;68(3-4):673-83.

[6] Liu L, Huang ZM, He C, Han X. Mechanical performance of laminated composites incorporated with nanofibrous membranes. Mater Sci Eng A 2006;435-436(0):309-17.

[7] Liu L, Huang ZM, Xu GY, Liang YM, Dong GH. Mode II interlaminar delamination of composite laminates incorporating with polymer ultra thin fibers. Polym Compos 2008;29(3):285-92.

[8] Lee SH, Lee JH, Cheong SK, Noguchi H. A toughening and strengthening technique of hybrid composites with non-woven tissue. J Mater Process Technol 2008;207(1-3):21-9.

[9] Lee SH, Noguchi H, KimYB, Cheong SK. Effect of interleaved non-woven carbon tissue on interlaminar fracture toughness of laminated composites: part 1: mode II. J Compos Mater 2002;36(18):2153-68.

[10] Zucchelli A, Gualandi C, Focarete ML, Donati L, Minak G, Ramakrishna S. Influence of electrospun Nylon 6,6 nanofibrous mats on the interlaminar properties of Gr-epoxy composite laminates. Compos Struct 2012;94(2):571-9.

[11] Zucchelli A, Focarete ML, Gualandi C, Ramakrishna S. Electrospun nanofibers for enhancing structural performance of composite materials. Polym Adv Technol 2011;22(3):339-49.

[12] Thostenson ET, Li WZ, Wang DZ, Ren ZF, Chou TW. Carbon nanotube/carbon fiber hybrid multiscale composites. J Appl Phys 2002;91:6034-7.

[13] Qian H, Greenhalgh ES, Shaffer MSP, Bismarck A. Carbon nanotube-based hierarchical composites: a review. J Mater Chem 2010;20(23):4751-62.

[14] Zeng QH, Yu AB, Lu GQ. Multiscale modeling and simulation of polymer nanocomposites. Prog Polym Sci 2008;33:191-269.

[15] Hu H, Onyebueke L, Abatan A. Characterizing and modeling mechanical properties of nanocomposites review and evaluation. J Miner Mater Characterization Eng 2010;9(4):275.

[16] LLorca J, González C, Molina-Aldareguía JM, Segurado J, Seltzer R, Sket F, et al. Multiscale modeling of composite materials: a roadmap towards virtual testing. Adv Mater 2011;23:5130-47.

[17] Loos MR, Schulte K. Is it worth the effort to reinforce polymers with carbon nanotubes? Macromol Theory Simul 2011;20:350-62.

[18] Ozden E, Menceloglu YZ, Papila M. Engineering chemistry of electrospun nanofibers and interfaces in nanocomposites for superior mechanical properties. ACS Appl Mater Interfaces 2010;2(7):1788-93.

[19] Ozden E, Menceloglu YZ, Papila M. Electrospun polymer/carbon nanotubes nanofibers reinforced composites. In: Materials Research Society proceedings; 2009.

[20] Albertsen H, Ivens J, Peters P, Wevers M, Verpoest I. Interlaminar fracture toughness of CFRP influenced by fibre surface treatment: part I. Experimental results. Compos Sci Technol 1995;54(2):133-45.

[21] Ozden E, Menceloglu YZ, Papila M. MWCNTs/P(St-co-GMA) composite nanofibers of engineered interface chemistry for epoxy matrix nanocomposites. ACS Appl Mater Interfaces 2011;4(2):777-84.

[22] Feng XJ, Jiang L. Design and creation of super wetting/anti wetting surfaces. Advanced Mater 2006;18(23):3063-78.

[23] Seyhan AT, Tanoglu M, Schulte K. Mode I and Mode II fracture toughness of eglass non-crimp fabric/carbon nanotube (CNT) modified polymer based composites. Eng Fract Mech 2008;75(18):5151-62.

[24] Stevanovic D, Kalyanasundaram S, Lowe A, Jar PY. Mode I and Mode II delamination properties of glass/vinyl-ester composite toughened by particulate modified interlayers. Compos Sci Technol 2003;63(13):1949-64. 